\title{
The relationship between cigarette smoking and obesity
}

\author{
Aziz Gümüiş ${ }^{a^{*}}$, Servet Kayhan ${ }^{\mathrm{a}}$, Halit Cinarka ${ }^{\mathrm{a}}$, Serap Baydur ${ }^{\mathrm{b}}$, Derya Grakoup ${ }^{\mathrm{a}}$, Ünal Şahin ${ }^{\mathrm{a}}$ \\ ${ }^{a}$ Department of Chest Disease, Faculty of Medicine, Recep Tayyip Erdoğan University, Rize, Turkey \\ ${ }^{b}$ Department of Endocrinology and Metabolic Diseases, Faculty of Medicine, Recep Tayyip Erdoğan University, Rize, Turkey
}

\section{ARTICLE INFO ABSTRACT}

\section{Article History}

Received $\quad 03 / 09 / 2013$

Accepted $\quad 08 / 10 / 2013$

\section{* Correspondence to: \\ Aziz Gümüş \\ Department of Chest Disease, \\ Faculty of Medicine, \\ Recep Tayyip Erdoğan University, \\ Rize, Turkey \\ e-mail: azizgumus@gmail.com}

\section{Keywords:}

Blood pressure

Body mass index

Obesity

Smoking
The cigarette smoking and the obesity are the main reasons of mortality and the morbidity. There are limited studies detecting the relationship between smoking and obesity. However the reported results are contradictory. The aim of the study is to investigate the effects of smoking on body mass index and obesity. A total of 983 patients consisting of $464(47 \%)$ male and 519 (53\%) female who admitted to department of chest disease outpatient clinic were enrolled in this study. The age, gender, body mass index (BMI), diastolic and systolic blood pressure levels and smoking states of the patients were recorded. The mean age of patients was $50.7 \pm 14.8$ years (range $20-80$ ). We detected the obesity in 359 (37\%) patients. Compared to smoker females, obesity rate was found significantly higher in non-smoker females $(\mathrm{p}<0.001)$. Similarly, there was also significant difference between the smoker and non-smoker males, which was lower than the female group $(\mathrm{p}=0.041)$. We found significantly lower BMI scores in female smokers, than non-smokers and ex-smokers group ( $\mathrm{p}=0.026$ and $\mathrm{p}<0.001$ respectively). Similar results were obtained in males ( $\mathrm{p}=0.019, \mathrm{p}<0.001$ respectively). There was a positive correlation between BMI and age, systolic and diastolic blood pressure. A negative correlation was found between BMI and smoking amount (pack-year) $(\mathrm{p}<0.001)$. Systolic and diastolic blood pressures were found to be lower in smokers than non-smokers in both genders $(\mathrm{p}<0.001)$. Cigarette smoking causes a decrease in body mass index, obesity rates and blood pressure levels. The substances found in cigarettes and the mechanism of action leading to these effects are unclear. There is a need for further studies on this topic.

J. Exp. Clin. Med., 2013; 30:311-315

(C) 2013 OMU

\section{Introduction}

Cigarette smoking and obesity are the main reasons of mortality and morbidity (Hodgson, 1992). They are associated with serious diseases, such as coronary heart disease, cerebrovascular disease and cancer (Calle et al., 2003). There is a strong genetic background to the development of obesity, while environmental factors are regarded as fundamental elements in rising obesity (Calle et al., 2000; Hill et al., 2000). A decrease in physical activity and an increase in high-energy food consumption are the dominant environmental factors. An increase in the incidence of obesity and a decrease in smoking levels are being observed in developed countries. Obesity levels in the United States of America have risen from $15 \%$ to $34 \%$ in the last three decades, while cigarette smoking levels have declined from $37 \%$ to $20 \%$ (Ogden et al., 2006).

The relation between cigarette smoking and obesity has been investigated in a number of studies. Smokers have generally been shown to have lower body mass indices and lower levels of obesity (Klesges et al., 1989; Rásky et al., 1996; Molarius and Seidel, 1997; Fang et al., 2009). An investigation about economic analysis of adult obesity reported an upward trend in obesity by rising the prices of cigarettes (Chou et al., 2004). The mechanisms to account for the reducing effect of cigarettes on body mass index and obesity levels are unclear. Cigarette smoking is thought to reduce obesity by affecting mechanisms associated with rates of food intake, physical activity and metabolism. However, there are also studies showing no correlation between cigarette smoking and obesity (Park, 2009; Saarni et al., 2009). Some studies have shown an increase in visceral fatty tissue, a major risk factor for cardiovascular disease, in cigarette smokers, while body mass index is unaffected (Yun et al., 2012). 


\begin{tabular}{|c|c|c|c|c|}
\hline Characteristic & $\begin{array}{c}\text { Smoker } \\
\mathrm{n}=\mathbf{3 7 1}\end{array}$ & $\begin{array}{c}\text { Ex-smoker } \\
\mathrm{n}=112\end{array}$ & $\begin{array}{c}\text { Non-smoker } \\
\mathbf{n}=\mathbf{5 0 0}\end{array}$ & $p$ \\
\hline Age(years) & $47 \pm 12$ & $55 \pm 13$ & $53 \pm 16$ & $<0.001$ \\
\hline BMI $\left(\mathrm{kg} / \mathrm{m}^{2}\right)$ & $26.4 \pm 4.7$ & $27.2 \pm 4.4$ & $30.0 \pm 6.0$ & $<0.001$ \\
\hline Cigarettes (p-y) & $29 \pm 18$ & $32 \pm 19$ & 0 & $<0.001$ \\
\hline SBP (mmHg) & $122 \pm 23$ & $136 \pm 24$ & $149 \pm 29$ & $<0.001$ \\
\hline DBP (mmHg) & $75 \pm 14$ & $82 \pm 12$ & $89 \pm 15$ & $<0.001$ \\
\hline
\end{tabular}

BMI: Body mass index; p-y: packet-years; SBP: Systolic blood pressure; DBP: Diastolic blood pressure.

One-Way ANOVA was used in the comparison of more than two groups

The correlation between cigarette smoking and obesity, two significant risk factors for cardiovascular diseases and cancer, is uncertain, and conflicting results exist. The purpose of this study was to investigate the effect of cigarette smoking on body mass index and obesity and to contribute to clarifying the subject.

\section{Materials and methods}

Patients who applied to the Recep Tayyip Erdoğan University Faculty of Medicine Chest Diseases Clinic in Turkey between 1 January and 30 June, 2013, and aged 20-80 were included. Patients' age, sex, height, weight, body mass index (BMI), diastolic and systolic blood pressures (DBP/SBP) and cigarette smoking status were recorded.

Exclusion criteria: Pregnant subjects, individuals receiving obesity treatment, using alcohol, with a diagnosis of hyper or hypothyroidism, receiving levothyroxine, propylthiouracil or methimazole therapy, with unexplained weight loss in the preceding one month, diagnosed with cancer, cirrhosis or chronic kidney insufficiency of severe and very severe chronic obstructive pulmonary disease (COPD) or receiving systemic corticosteroid therapy were excluded.

\section{Measurements:}

1. Blood pressure: Two measurements of DBP and SBP were taken, at 5-min intervals after at least 15-min rest, from the left arm using a sphygmomanometer device (ERKA Perfect-Aneroid model blood pressure measurement. Germany). Means of the two measurements were recorded as mean SBP and DBP.

2. Body mass index: Patients' weight and height were measured, and BMI was calculated using the formula weight $(\mathrm{kg})$ / height(meters $)^{2}$.

Definition: The terms of smoker, ex-smoker, non-smoker were defined according to Michelle et al. (2007).

Smokers: Individuals who had smoked more than 100 cigarettes in their lives and who still continued to smoke.

Ex-smokers: Individuals who had smoked more than 100 cigarettes in their lives and who were no longer smoking.

Non-smokers: Individuals who had smoked fewer than 100 cigarettes in their lives.

Obesity: Defined as having a body mass index of 30 or above.

\section{Statistical analysis}

Statistical analyses were performed using SPSS (SPSS version 16; SPSS Inc., Chicago, IL, USA). Constant variables are expressed as mean $\pm \mathrm{SD}$, and categoric variables as $\%$. One-Way ANOVA and post hoc Tukey-HSD were applied in the comparison of means from more than two groups. The chi square test was used to compare rates. Pearson correlation analysis was performed to assess the correlation of parametric variables and linear regression analysis to identify factors affecting dependent variables. $\mathrm{P}<0.05$ was regarded as significant.

\section{Results}

Nine hundred eighty-three patients, 519 (53\%) female and $464(47 \%)$ male were included. Mean age was 50.7 \pm 14.8 years. Three hundred seventy-one $(38 \%)$ patients were still smoking, $112(11 \%)$ had quit and $500(51 \%)$ were non-smokers. Demographic characteristics of the study groups were shown in Table 1. The mean values of BMI, SBP and DBP were found to be lower in smokers compared to ex-smokers and non-smokers $(\mathrm{p}<0.001)$ and in ex-smokers compared

Table 2. Demographic characteristics of the groups according to genders

\begin{tabular}{|c|c|c|c|c|c|c|c|c|}
\hline & & $\begin{array}{c}\text { Female } \\
n=519\end{array}$ & & $p$ & & $\begin{array}{c}\text { Male } \\
n=464\end{array}$ & & $p$ \\
\hline & $\begin{array}{c}\text { Smoker } \\
n=123\end{array}$ & $\begin{array}{c}\text { Ex-smoker } \\
\mathbf{n}=\mathbf{2 2}\end{array}$ & $\begin{array}{c}\text { Non-smoker } \\
\mathbf{n}=\mathbf{3 7 4}\end{array}$ & & $\begin{array}{c}\text { Smoker } \\
\mathrm{n}=\mathbf{2 4 8}\end{array}$ & $\begin{array}{c}\text { Ex-smoker } \\
\text { n=90 }\end{array}$ & $\begin{array}{c}\text { Non-smoker } \\
n=126\end{array}$ & \\
\hline Age, year & $43 \pm 10$ & $48 \pm 10$ & $52 \pm 16$ & $\begin{array}{c}0.236^{\mathrm{a}} \\
<0.001^{\mathrm{b}} \\
0.397^{\mathrm{c}}\end{array}$ & $48 \pm 13$ & $56 \pm 13$ & $54 \pm 17$ & $\begin{array}{c}<0.001^{\mathrm{a}} \\
0.002^{\mathrm{b}} \\
0.351^{\mathrm{c}}\end{array}$ \\
\hline BMI $\left(\mathbf{k g} / \mathbf{m}^{2}\right)$ & $27.1 \pm 5.1$ & $30.7 \pm 6.1$ & $30.8 \pm 6.2$ & $\begin{array}{c}0.026^{\mathrm{a}} \\
<0.001^{\mathrm{b}} \\
0.999^{\mathrm{c}}\end{array}$ & $26.1 \pm 4.4$ & $27.6 \pm 4.4$ & $28.1 \pm 4.5$ & $\begin{array}{c}0.019^{\mathrm{a}} \\
<0.001^{\mathrm{b}} \\
0.687^{\mathrm{c}}\end{array}$ \\
\hline Cigarettes (p-y) & $21 \pm 5$ & $17 \pm 4$ & 0 & $0.808^{\mathrm{a}}$ & $34 \pm 8$ & $36 \pm 9$ & 0 & $0.658^{\mathrm{a}}$ \\
\hline SBP (mmHg) & $121 \pm 22$ & $139 \pm 24$ & $151 \pm 30$ & $\begin{array}{c}0.013^{\mathrm{a}} \\
<0.001^{\mathrm{b}} \\
0.158^{\mathrm{c}}\end{array}$ & $121 \pm 23$ & $134 \pm 24$ & $144 \pm 24$ & $\begin{array}{c}<0.001^{\mathrm{a}} \\
<0.001^{\mathrm{b}} \\
0.001^{\mathrm{c}}\end{array}$ \\
\hline DBP (mmHg) & $75 \pm 13$ & $83 \pm 12$ & $89 \pm 16$ & $\begin{array}{c}0.069^{\mathrm{a}} \\
<0.001^{\mathrm{b}} \\
0.099^{\mathrm{c}}\end{array}$ & $75 \pm 15$ & $82 \pm 12$ & $87 \pm 12$ & $\begin{array}{c}0.001^{\mathrm{a}} \\
<0.001^{\mathrm{b}} \\
0.019^{\mathrm{c}}\end{array}$ \\
\hline
\end{tabular}

BMI: Body mass index; p-y: packet-years; SBP: Systolic blood pressure; DBP: Diastolic blood pressure

a: Comparing the smoker and ex-smoker groups.

b: Comparing the smoker and non-smoker groups.

c: Comparing the ex- and non-smoker groups.

One-Way ANOVA was used in the comparison of more than two groups and the Post Hoc Turkey method in paired group analyses 
Table 3. Pearson correlation results between BMI and other parameters

\begin{tabular}{ccccc} 
& Age & Cigarettes (p-y) & SBP & DBP \\
\hline BMI $\left(\mathbf{k g} / \mathbf{m}^{2}\right)$ & $\mathrm{r}=0.285$ & $\mathrm{r}=-0.225$ & $\mathrm{r}=0.509$ & $\mathrm{r}=0.505$ \\
& $\mathrm{p}<0.001$ & $\mathrm{p}<0.001$ & $\mathrm{p}<0.001$ & $\mathrm{p}<0.001$ \\
\hline
\end{tabular}

to non-smokers $(\mathrm{p}<0.001)$. In this study, the mean age of the smokers were lower than that of the non-smokers and ex-smokers, so we performed the univariate covariance analysis of data after exclusion the age factor and again BMI, SBP and DBP were found to be significantly low in smokers compared to non-smokers and ex-smokers $(\mathrm{p}<0.001)$. The number of smokers was $248(53 \%)$ males and $123(24 \%)$ females. Ex-smokers consisted of 90 (19\%) males and 22 $(4 \%)$ females. The numbers of smokers and ex-smokers were significantly higher in men compared to women $(\mathrm{p}<0.001)$. Length of time since quitting among the 112 ex-smokers was 7.1 \pm 6.7 years (median 5 years, range 1-30 years).

BMI was found to be higher in non-smokers and ex-smokers compared to smokers in both genders. In women it was significantly lower in the smoker group compared to the exand non-smokers $(\mathrm{p}=0.026, \mathrm{p}<0.001$ respectively for female group and $p=0.019, p<0.001$ respectively for female group).

Differences based on smoking status were observed in blood pressures. SBP and DBP in women were significantly lower in smokers compared to non-smokers $(\mathrm{p}<0.001)$. SBP and DBP were lower in ex-smokers compared to non-smokers, although the difference was not statistically significant ( $\mathrm{p}=0.158$ and $\mathrm{p}=0.099$, respectively). Among men, both SBP and DBP in the smoker group were significantly lower compared to both ex- and non-smokers. In addition, blood pressures were lower in ex-smokers compared to non-smokers. The demographic characteristics of the men and women in the groups established on the basis of smoking status are shown separately in table 1 .

The correlation between BMI and age, amount of cigarettes smoked (packege-years), SBP and DBP in the 983 patients in the study was investigated using Pearson correlation analysis. BMI was positively correlated with age, SBP and DBP and negatively correlated with amount of cigarettes smoked. The results are shown in table 2. Linear regression analysis was performed in order to separately determine the variables affecting BMI in both genders. In women, only age was determined as an independent predictor of BMI (beta $=0.420$, $\mathrm{p}<0.001$ ), while in men age and amount of cigarettes smoked were identified as independent variables affecting BMI. The regression analysis results are shown in Table 3.
Obesity levels were investigated in groups established on the basis of smoking status. Obesity was determined in $359(37 \%)$ of the 983 patients, 254 (49\%) women and 105 (23\%) men. Obesity levels were significantly higher in women than in men. Obesity levels were significantly elevated in non-smokers compared to smokers in both genders $(\mathrm{p}<0.001)$. Obesity was determined in $38(31 \%)$ smoking women and $46(16 \%)$ smoking men $(\mathrm{p}=0.007)$. Similarly, obesity levels were significantly higher in non-smoking women compared to non-smoking men $(\mathrm{p}<0.001)$. Obesity levels by sex and cigarette smoking status are shown in table 4 and Figure 1.

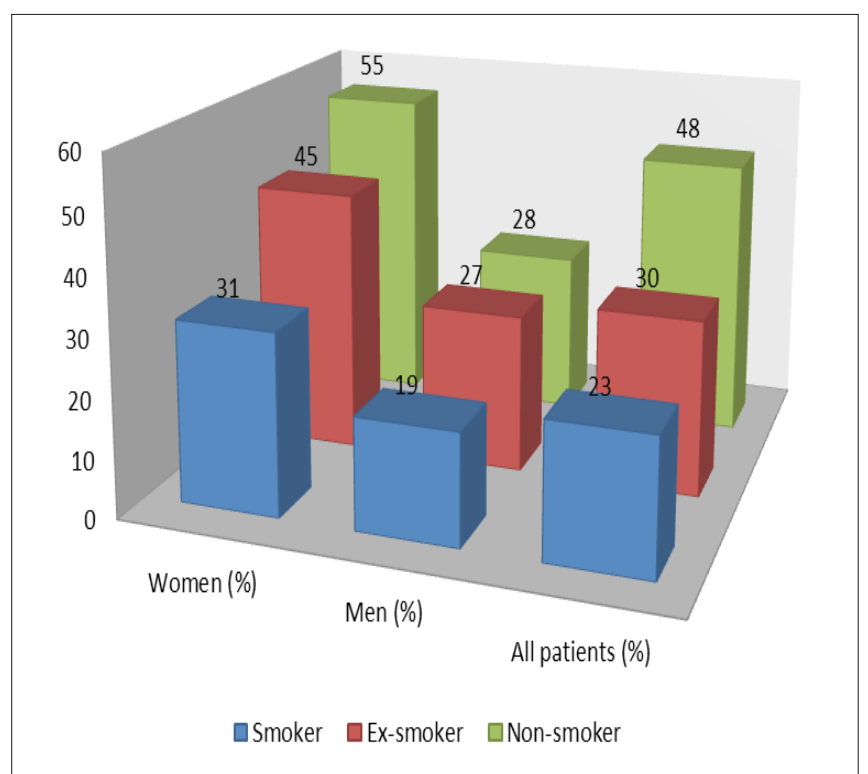

Fig. 1. Comparison of the percentage of the obesity (BMI $>=30 \mathrm{~kg} /$ $\mathrm{m}^{2}$ ) according to gender and cigarette smoking status.

\section{Discussion}

We investigated the relation between cigarette smoking and obesity, two important risk factors for cardiovascular diseases and cancer. BMI and obesity levels were lower in male and female smokers compared to non-smokers. Demographic features of our study group have similarities with the study of Rasky et al. (1996) with a large study population containing of 27344 persons. The mean age of the females was 48.5 years in non-smokers, 44 years in ex-smokers and 37.4 years in smokers where the mean age of the males as follows 43, 56 and 41.6 years respectively. The mean ages of non-smoker, ex-smoker and smoker groups were found as 52, 48 and 43 years in females and 54, 56 and 48 years in males respectively. The mean age of the smokers were relatively low in both population. Sulander et al. (2007) monitored their patients

\begin{tabular}{|c|c|c|c|c|c|c|c|}
\hline \multirow[t]{2}{*}{ Sex } & \multicolumn{2}{|c|}{$\begin{array}{c}\text { Smokers } \\
(n=371)\end{array}$} & \multicolumn{2}{|c|}{$\begin{array}{l}\text { Ex-Smokers } \\
\quad(n=112)\end{array}$} & \multicolumn{2}{|c|}{$\begin{array}{c}\text { Non-Smokers } \\
(\mathbf{n}=\mathbf{5 0 0})\end{array}$} & \multirow[t]{2}{*}{$p$} \\
\hline & $\mathrm{BMI}<30$ & $\mathrm{BMI} \geq 30$ & $\mathrm{BMI}<30$ & $\mathrm{BMI} \geq \mathbf{3 0}$ & $\mathrm{BMI}<30$ & $\mathrm{BMI} \geq 30$ & \\
\hline Female (n) & 85 & 38 & 12 & 10 & 168 & 206 & $\begin{array}{c}0.181^{\mathrm{a}} \\
<0.001^{\mathrm{b}} \\
0.378^{\mathrm{c}}\end{array}$ \\
\hline Male (n) & 202 & 46 & 66 & 24 & 91 & 35 & $\begin{array}{l}0.104^{\mathrm{a}} \\
0.041^{\mathrm{b}} \\
0.857^{\mathrm{c}}\end{array}$ \\
\hline $\begin{array}{l}\text { Chi-square } \\
\text { a: Compar } \\
\text { b: Compar } \\
\text { c: Compar }\end{array}$ & $\begin{array}{l}\text { moker a } \\
\text { moker ar } \\
x-\text { and } n\end{array}$ & $\begin{array}{l}\text { x-smoker g } \\
\text { n-smoker } \\
\text { moker gro }\end{array}$ & & & & & \\
\hline
\end{tabular}


for 10 years and showed that obesity levels were lower in smokers compared to non-smokers. The results of that study are compatible with ours. Feng et al. (2010) reported lower BMI and obesity levels in smokers compared to ex- and non-smokers. The results of that important study are also similar to ours. However, there are certain differences. Obesity levels in our study were significantly lower among both male and female smokers compared to non-smokers, while no difference was determined in terms of obesity between smokers and ex-smokers.

One of the noteworthy results of our study is the negative correlation between amount of cigarettes smoked and BMI. Linear regression analysis showed that amount smoked was an independent variable affecting BMI in men only. We think that similar results will emerge in women as amount smoked and duration of smoking increase.

Analysis of the results of this study as a whole suggests that cigarette smoking is a preventive factor for obesity. The mechanism involved is unclear. However cigarette smoking may operate by causing a decrease in food intake and/or by increasing metabolic rate. With the current level of knowledge, the harmful effects of smoking of course far exceed the benefits obtained from quitting (Xu et al., 2007). Obesity has become an important cause of mortality and morbidity that has increased in epidemic proportions across the world in recent years. All the environmental factors affecting obesity, including smoking, must be established. In a study of 92,175 patients, Freedman et al. (2006) showed higher mortality from all causes in non-smoking but very obese (BMI>35) patients aged over 65 compared to smokers of normal weight. As expected, cigarette smoking was shown to be a more important factor than obesity in the development of cancer and cancer-related deaths. That wide-ranging study showed the extent to which obesity threatens health. It is thought to be a more important health problem than cigarettes, particularly in cases aged over 65 .

The results of our study may give some idea of the prevalence of obesity in society. Qin et al. (2013) recently reported a prevalence of obesity in hypertensive patients of $13.7 \%$ in women and $6.7 \%$ in men. Sulander et al. (2007) reported a prevalence of obesity of $14.7 \%$ in their entire study group, while in a study of more than one million individuals, Goday-Arnó et al. (2013) reported a prevalence of obesity of $16.4 \%$ and of overweight of $40.5 \%$. Obesity levels in the
USA are approximately 34\% (Ogden et al., 2006). The obesity level in our study was $37 \%$. This is quite high. It was significantly higher in women compared to men (49\% vs $23 \%$ ). Obesity and related complications are common public health problems in Turkish society.

Another important finding from our study is that SBP and DBP were lower in smokers than in non-smokers. Correlation analysis revealed a negative correlation between blood pressures and amount of cigarettes smoked, and a strong positive correlation between BMI and blood pressures. Blood pressure rises with BMI and decreases as the amount of cigarettes smoked declines. Although many studies have been performed, the effect of smoking on blood pressure is still unclear. In addition to studies showing that it raises blood pressure, others have reported that it has no effect or else reduces blood pressure. Lee et al. (2001) showed that blood pressure rises in people who stop smoking. Our results are compatible with those of that study.

There are significant limitations to our study. First is the low patient numbers involved, 983 . The numbers of female smokers and ex-smokers are particularly insufficient. Levels of cigarette smoking and obesity in society are high. Further prospective studies and greater patient numbers are clearly needed in order to produce clearer results concerning these problems with such high prevalences. The second limitation is that only patients applying to the chest diseases clinic were included. These cases may not reflect all of society. Society-based epidemiological studies are needed from that perspective. However, ours can be regarded as a pioneering study showing a relation between smoking and obesity. Our scan of the literature revealed no previous such study performed in Turkish society.

In conclusion, cigarette smoking, obesity and elevated blood pressure, three important causes of mortality and morbidity, are inter-related. Interestingly, as the level of cigarettes smoked rises, BMI, obesity levels and blood pressures decrease. We think that cigarette smoking has a property that prevents obesity and lowers blood pressure. Wide-ranging and prospective studies are needed to elucidate this. It is impossible with our present state of knowledge to state the mechanism by which smoking affects these results. The mechanism and other benefit/loss characteristics of cigarette smoking apart from cancer need to be investigated.

\section{REFERENCES}

Calle, E.E., Rodriguez, C., Walker-Thurmond, K., Thun, M.J., 2003. Overweight, obesity and mortality from cancer in a prospectively studied cohort of U.S.adults. N. Engl. J. Med. 348, 1625-1638.

Calle, J., Wulftange, H., Goerg, T., Ziegler, A., Hinney, A., Barth, N., 2000. Epidemic obesity: Are genetic factors involved via increased rates of assortative mating? Int. J. Obes. Relat. Metab. Disord. 24, 345-353.

Chou, S.Y., Grossman, M., Saffer, H., 2004. An economic analysis of adult obesity: Results from the Behavioral Risk Factor Surveillance System. J. Health. Econ. 23, 565-587.

Fang, H., Ali, M.M., Rizzo, J.A., 2009. Does smoking affect body weight and obesity in China? Econ. Hum. Biol. 7, 334-350.

Feng, L., Ning, Z., Kai-Wen, C., Hua, W., 2010. Reduced smoking and rising obesity: Does smoking ban in the workplace matter? Economics Letters.108, 249-252.

Freedman, D.M., Sigurdson, A.J., Rajaraman, P., Doody, M.M., Linet, M.S., Ron, E., 2006. The mortality risk of smoking and obesity combined. Am. J. Prev. Med. 3, 355-362.

Goday-Arnó, A., Calvo-Bonacho, E., Sánchez-Chaparro, M.A., Gelpi, J.A., Sainz, J.C., Santamaría, S., Navarro, R.I., Gutiérrez, F., Sanz, C., Caveda, E., Reviriego, J., 2013. High prevalence of obesity in a Spanish working population. Endocrinol. Nutr. 60, 173-178.

Hill, J.O., Melanson, E.L., Wyatt, H.T., 2000. Dietary fat intake and regulation of energy balance: Implications for obesity. J. Nutr. 130, $284-288$. Hodgson, T.A., 1992. Cigarette smoking and lifetime medical expenditures. Milbank. Q. 70, 81-125.

Klesges, R.C., Meyers, A.W., Klesges, L.M., La Vasque, M.E., 1989. Smoking, body weight, and their effects on smoking behavior: A 
comprehensive review of the literature. Psychol. Bull. 106, 204-230.

Lee, D.H., Ha, M.H., Kim, J.R., Jacobs, D.R., 2001. Effects of smoking cessation on changes in blood pressure and incidence of hypertension: A 4-year follow-up study. Hypertension. 37, 194-198.

Michelle, M., Janet, E.F., David, E.N., Harold, W.K., 2007. Cigarette smoking status and the association between media use and overweight and obesity. Am. J. Epidemiol. 166, 795-802.

Molarius, A., Seidell, J.C., 1997. Differences in the association between smoking and relative body weight by level of education. International Journal of Obesity. 21, 189-196.

Ogden, C.L., Carroll, M.D., Curtin, L.R., McDowell, M.A., Tabak, C.J., Flegal, K.M., 2006. Prevalence of overweight and obesity in the United States, 1999-2004. JAMA. 295, 1549-1555.

Park, E., 2009. Gender as a moderator in the association of body weight to smoking and mental health. Am. J. Public Health. 99, 146-151.

Qin, X., Zhang, Y., Cai, Y., He M., Sun, L., Fu, J., 2013. Prevalence of obesity, abdominal obesity and associated factors in hypertensive adults aged 45-75 years. Clin. Nutr. 32, 361-367.

Rásky, E., Stronegger, W.J., Freidl, W., 1996. The relationship between body weight and patterns of smoking in women and men. Int. J. Epidemiol. $25,1208-1212$.

Saarni, S.E., Pietilainen, K.H., Kantonen, S., Rissanen, A., Kaprio, J., 2009. Association of smoking in adolescence with abdominal obesity in adulthood: A follow-up study of 5 birth cohorts of Finnish Twins. Am. J. Public Health. 99, 348-354.

Sulander, T., Rahkonen, O., Nissinen, A., Uutela, A., 2007. Association of smoking status with obesity and diabetes among elderly people. Arch. Gerontol. Geriatr. 45, 159-167.

Xu, F., Yin, X.M., Wang, Y., 2007. The association between amount of cigarettes smoked and overweight, central obesity among Chinese adults in Nanjing, China. Asia Pac. J. Clin. Nutr. 16, 240-247.

Yun, J.E., Kimm, H., Choi, Y.J., Jee, S.H., Huh, K.B., 2012. Smoking is associated with abdominal obesity, not overall obesity, in men with type 2 diabetes. J. Prev. Med. Public. Health. 45, 316-322. 